Article

\title{
Improving the Assessment of Neonatal Abstinence Syndrome (NAS)
}

\author{
Claire A. Chin Foo ${ }^{1, *}$, Lynne M. Dansereau ${ }^{1}$, Katheleen Hawes ${ }^{1,2}$, Erica L. Oliveira ${ }^{1}$ and Barry M. Lester ${ }^{1,2,3, *}$ \\ 1 Brown Center for the Study of Children at Risk, Brown Alpert Medical School and Women and Infants \\ Hospital, Providence, RI 02912, USA; LDansereau@wihri.org (L.M.D.); KHawes@Wihri.org (K.H.); \\ EOliveira@Wihri.org (E.L.O.) \\ 2 Department of Pediatrics, Brown Alpert Medical School and Women and Infants Hospital, Providence, \\ RI 02908, USA \\ 3 Department of Psychiatry and Human Behavior, Brown Alpert Medical School, Providence, RI 02912, USA \\ * Correspondence: claire_Chin_Foo@Brown.edu (C.A.C.F.); Barry_Lester@Brown.edu (B.M.L.); \\ Tel.: +1-(401)-274-1122 (ext. 48901) (B.M.L.)
}

check for updates

Citation: Chin Foo, C.A.; Dansereau, L.M.; Hawes, K.; Oliveira, E.L.; Lester B.M. Improving the Assessment of Neonatal Abstinence Syndrome (NAS). Children 2021, 8, 685. https:// doi.org/10.3390/children8080685

Academic Editors: Ju-Lee Oei and Karel Allegaert

Received: 12 June 2021

Accepted: 4 August 2021

Published: 9 August 2021

Publisher's Note: MDPI stays neutral with regard to jurisdictional claims in published maps and institutional affiliations.

Copyright: (C) 2021 by the authors Licensee MDPI, Basel, Switzerland. This article is an open access article distributed under the terms and conditions of the Creative Commons Attribution (CC BY) license (https:// creativecommons.org/licenses/by/ $4.0 /)$

\begin{abstract}
Neonatal Abstinence Syndrome (NAS) is a public health problem of epidemic proportions. The Finnegan Neonatal Abstinence Scoring System (FNASS) is the tool most widely used to evaluate NAS. However, it is limited by its lack of interrater reliability and standardized approach. Surveys to evaluate the FNASS were distributed to nurses at the Women and Infants Hospital in Providence, RI, USA. Infants $(n=78)$ treated for NAS and born to methadone-maintained mothers were examined to compare items administered from the FNASS and the NICU Network Neurobehavioral Scale (NNNS). All nurses reported that the FNASS was somewhat to very subjective. More than half reported that it was somewhat to not accurate and a new scoring method is needed to accurately diagnose NAS. Correlations between FNASS items and NNNS items showed 9 of $32(28.1 \%)$ correlations were strong $\left(r_{\mathrm{s}}>0.5\right), 5$ of $32(15.6 \%)$ were moderate $\left(0.3<\mathrm{r}_{\mathrm{S}}<0.5\right)$, and 10 of $32(31.3 \%)$ were weak $\left(0.1<\mathrm{r}_{\mathrm{s}}<0.3\right)$. Principal component factor analysis (PCA) of the NNNS explained more variance (35.1\%) than PCA of NNNS and FNASS items combined (33.1\%). The nursing survey supported the need for developing a more objective exam to assess NAS. NNNS exam items may be used to improve the evaluation of NAS.
\end{abstract}

Keywords: Neonatal Abstinence Syndrome (NAS); Neonatal Opioid Withdrawal Syndrome (NOWS); Finnegan Neonatal Abstinence Scoring System (FNASS); NICU Network Neurobehavioral Scale (NNNS)

\section{Introduction}

Opioid use during pregnancy has reached epidemic proportions with a $242 \%$ increase in the last 10 years [1]. Increases in maternal opioid use have been accompanied by a parallel increase in the drug withdrawal of opioid-exposed infants, known as Neonatal Abstinence Syndrome (NAS), or more recently, Neonatal Opioid Withdrawal Syndrome (NOWS) [2,3]. From 2000 to 2016, the incidence of NAS increased sevenfold from 1.2 to 8.8 per 1000 hospital births [2-4]. Hospital costs for NAS have increased more than sixfold since 2004, resulting in approximately $\$ 2$ billion in excess costs primarily due to longer lengths of hospital stays [4].

The accurate diagnosis of NAS is critical because diagnosis of NAS typically leads to pharmacological as well as non-pharmacological treatment and an increased length of stay (LOS), which can result in additional exposure to opioids, affect the developing motherinfant relationship, and increase hospital costs. The most commonly used tool to evaluate the clinical manifestations in infants with NAS is the Finnegan Neonatal Abstinence Scoring System (FNASS), including modification, a 31-item list of signs and symptoms of three dimensions of withdrawal (Central Nervous System Disturbances; Metabolic, Vasomotor 
\& Respiratory Disturbances; and Gastrointestinal Disturbances) based on record review, maternal reports, and direct observation [5-7]. However, limitations of the FNASS have been described, including a lack of interrater reliability and subsequent validation, as well as a lack of a standardized approach [7-9]. The current tools used to measure NAS, including the FNASS, have often been described as subjective and highly variable due to poor reliability, particularly for nurses who do not often care for babies with NAS [10,11].

The NICU Network Neurobehavioral Scale (NNNS) is a standardized, comprehensive evaluation that incorporates neurologic and behavioral measures and signs of stress [12] The NNNS was originally developed as a research assessment for infants with prenatal cocaine and/or opioid exposure as part of the multisite longitudinal NIH Maternal Lifestyle Study. The NNNS has subsequently been used extensively across a broad spectrum of substance-exposed and other at-risk infant populations, is sensitive to NAS onset [13] and pharmacological treatment for NAS [14], as well as prenatal opiate exposure, and predicts developmental outcomes through age $41 / 2$ in this population [15]. Many of the symptoms of NAS that are scored on the FNASS are also scored on the NNNS. The NNNS is an objective, reliable, well-validated tool that is also used clinically with high-risk infants, including those with prenatal opioid exposure. An NNNS-based assessment may lead to improvements in the assessment and diagnosis of NAS and improve the management and treatment of this vulnerable population. In the current study, we conducted a survey about the FNASS with nurses who administer the exam, and we examined the relationship between FNASS and NNNS items measured in the same infants with NAS. The aim of the study was to determine if relations between Finnegan and NNNS items could lead to the development of an improved assessment of NAS.

\section{Materials and Methods}

Participants for the survey were 41 nurses who administer the FNASS in the MotherBaby unit at the Women and Infants Hospital in Providence, Rhode Island. Because the survey was anonymous, we do not have information on the demographics of the participants, with the exception of the number of years they have been nurses and the number of years they have performed the FNASS. The survey we developed consisted of 15 questions that covered years of nursing experience, accuracy of the FNASS, subjectivity, and difficulty in scoring the items on the FNASS. The survey was developed by the first and third authors. Dr. Hawes is an advanced practice nurse with more than 13 years' experience in nursing professional development and research in surveying nurse attitudes and perceptions related to the work environment and professional nursing practice. The survey was original and not tested previously. The survey included all the items on the FNASS to determine which ones the nurses found most subjective, which were most difficult to score, and which were most indicative of NAS (Supplementary Materials). Nurses completed the survey online or by depositing a paper copy into a survey-labeled sealed box in the nurses' lounge. The study received IRB exemption due to the lack of personal health information or identifiable information about the participants.

The NNNS and FNASS comparison included 78 infants treated for NAS born to methadone-maintained mothers. Study details were explained, and informed consent was obtained in accordance with the institutional review board. Exclusion criteria were infant congenital anomalies or gestational age $<35$ weeks, or maternal psychiatric problems that jeopardized informed consent. The FNASS was performed as part of standard care. FNASS training consists of studying the FNASS tool and instructions prior to observing experienced FNASS preceptors. Nurses observed their preceptors for three shifts (24-36 h total). During the training period the nurses score babies for interrater reliability with their preceptors. After the three-shift training period, nurses typically begin to score the FNASS on their own. The FNASS score was calculated by the nurse every $4 \mathrm{~h}$ from $2 \mathrm{~h}$ of age until 2 days after pharmacological treatment with morphine was discontinued. FNASS exams were administered throughout the infants' length of stay and NNNS exams were administered prior to NAS treatment. Drug treatment began when 2 consecutive FNASS 
scores were $\geq 8$. Drug treatment included oral neonatal morphine solution $(0.4 \mathrm{mg} / \mathrm{mL})$. The NNNS was performed before the FNASS 73\% of the time with at least an hour in between exams. The NNNS is a $20-30 \mathrm{~min}$ well-validated exam that assesses active and passive muscle tone, primitive reflexes, movement, social behaviors (e.g., cuddling and soothability), attention to visual and auditory stimuli, and a checklist of stress signs organized by organ systems. The NNNS items are summarized into the following scales: Habituation, Attention, Arousal, Regulation, Handling, Quality of Movement, Excitability, Lethargy, Nonoptimal Reflexes, Asymmetric Reflexes, Hypertonicity, Hypotonicity, and Stress Abstinence. The NNNS was administered by trained NNNS examiners who were recertified every 6 months. The NNNS exam was matched to the FNASS that was closest in time to NNNS administration or the time of the last feed.

Maternal and infant characteristics were summarized using frequencies for categorical characteristics and means for continuous characteristics. FNASS and NNNS data were analyzed using SPSS software v24. [16]. Spearman rank-order correlation was used to measure the strength and direction of the association between FNASS and NNNS individual items. FNASS items and NNNS summary scale items were compared by organ system and items selected from the NNNS exam measured similar signs and symptoms as that of the FNASS. Items were strongly correlated at $r_{\mathrm{s}}>0.5$, moderately correlated at $0.3<\mathrm{r}_{\mathrm{s}}<0.5$, and weakly correlated at $0.1<\mathrm{r}_{\mathrm{S}}<0.3$. Principal component factor analysis (PCA) with varimax rotation was used to define the underlying structure among FNASS items and NNNS items that measure similar signs and symptoms with minimal information loss. We used a loading of $>0.40$ to interpret the factor patterns.

\section{Results}

\subsection{Nursing Survey}

All nurses (100\%) reported that the FNASS was "somewhat" to "very" subjective with more than half (56\%) reporting that the FNASS was "somewhat" accurate to "not accurate at all". The majority of the nurses (90\%) thought that performing FNASS in the mother's room compared to performing the FNASS in the nursery would impact the baby's score. Half of the nurses $(50 \%)$ thought that there were many nurse-to-nurse disagreements in the FNASS scoring system between nurses in the same unit of the hospital. When asked to describe the FNASS, $40 \%$ of nurses thought the FNASS was subjective and $57.6 \%$ of the nurses had a negative opinion of the FNASS in terms of length, complexity, and reliability. More than half of the nurses (51\%) thought that there is a need for a new scoring method to diagnose NAS. We compared nurses' years of performing the FNASS and years of nursing experience to the survey responses. Answers to the survey questions did not differ significantly by years of nursing experience or years of performing the FNASS $(p>0.05)$.

\subsection{FNASS and NNNS}

The majority of the infants' mothers were white (91\%), and 16.7\% had not completed high school. The average gestational age of the infants was 38.4 weeks and $59 \%$ were male (Table 1).

Table 1. Maternal and infant characteristics at birth.

\begin{tabular}{lc}
\hline$n(\%)$ or Mean (SD) & $n=78$ \\
\hline Maternal characteristics & \\
Race & $2(2.6 \%)$ \\
African American & $71(91.0 \%)$ \\
White & \\
\hline
\end{tabular}


Table 1. Cont.

\begin{tabular}{lc}
\hline $\boldsymbol{n}(\boldsymbol{\%})$ or Mean (SD) & $n=78$ \\
\hline Other & $5(6.4 \%)$ \\
\hline Maternal age (yrs.) & $29.1(5.7)$ \\
Education, <12 years & $13(16.7 \%)$ \\
Parity & $2.4(1.3)$ \\
Infant characteristics & \\
Gender, male & $46(59.0 \%)$ \\
Gestational age (wk.) & $38.4(1.8)$ \\
Birth weight (g) & $2968(621)$ \\
Length (cm) & $48.6(2.8)$ \\
Head circumference (cm) & $33.5(2.9)$ \\
Apgar score, minute 1 & $7.5(1.6)$ \\
Apgar score, minute 5 & $8.7(0.6)$ \\
\hline
\end{tabular}

Spearman rank-order correlations between items that measured similar constructs from both the FNASS and the NNNS summary scores were conducted to determine which items were most closely related (Table 2). Nine out of $32(28.1 \%)$ items were strongly correlated $\left(\mathrm{r}_{\mathrm{s}}>0.5\right), 5$ out of $32(15.6 \%)$ were moderately correlated $\left(0.3<\mathrm{r}_{\mathrm{s}}<0.5\right)$, and 10 out of $32(31.3 \%)$ were weakly correlated $\left(0.1<r_{\mathrm{S}}<0.3\right)$.

Table 2. Correlations between Finnegan and NNNS items.

\begin{tabular}{|c|c|c|c|}
\hline Finnegan Item & NNNS Scale Item & $\begin{array}{l}\text { Correlation Between } \\
\text { Finnegan and NNNS } \\
\text { Item }\end{array}$ & $p$-Value \\
\hline \multicolumn{4}{|l|}{ Central Nervous System Disturbances } \\
\hline \multirow{6}{*}{ Crying } & High-pitched cry ${ }^{* * *}$ & 0.827 & $<0.001$ \\
\hline & Predominant state ${ }^{* * *}$ & 0.732 & $<0.001$ \\
\hline & Consolability & 0.304 & 0.36 \\
\hline & Peak of excitement * & 0.256 & $<0.001$ \\
\hline & Rapidity of buildup ** & 0.452 & $<0.001$ \\
\hline & Irritability $* *$ & 0.334 & $<0.001$ \\
\hline Reflexes & Moro reflex $* * *$ & 0.705 & $<0.001$ \\
\hline \multirow[t]{3}{*}{ Tremors undisturbed-mild-severe } & Tremulousness & 0.089 & 0.41 \\
\hline & $\begin{array}{l}\text { Low frequency/high } \\
\text { amplitude *** }\end{array}$ & 0.791 & $<0.001$ \\
\hline & $\begin{array}{l}\text { High frequency/low } \\
\text { amplitude* }\end{array}$ & 0.237 & $<0.001$ \\
\hline \multirow[t]{3}{*}{ Tremors disturbed-mild-severe } & Tremulousness* & 0.162 & 0.04 \\
\hline & $\begin{array}{l}\text { Low frequency/high } \\
\text { amplitude }\end{array}$ & 0.417 & $<0.001$ \\
\hline & $\begin{array}{l}\text { High frequency/low } \\
\text { amplitude* }\end{array}$ & 0.228 & $<0.001$ \\
\hline \multirow[t]{6}{*}{ Muscle tone } & General tone & 0.139 & 0.02 \\
\hline & Leg Resistance & 0.074 & 0.19 \\
\hline & Popliteal angle * & 0.165 & $<0.001$ \\
\hline & Scarf sign * & 0.192 & $<0.001$ \\
\hline & Forearm resistance & 0.089 & 0.12 \\
\hline & Truncal tone * & 0.174 & $<0.001$ \\
\hline Excoriation & Excoriations $* * *$ & 0.749 & $<0.001$ \\
\hline Myoclonic jerk & Myoclonic jerks & - & - \\
\hline Generalized convulsions & Generalized seizures & - & - \\
\hline
\end{tabular}


Table 2. Cont.

\begin{tabular}{llcc}
\hline Finnegan Item & NNNS Scale Item & $\begin{array}{l}\text { Correlation Between } \\
\text { Finnegan and NNNS } \\
\text { Item }\end{array}$ & $\begin{array}{l}p \text { - } \\
\text { Value }\end{array}$ \\
\hline $\begin{array}{l}\text { Metabolic, Vasomotor \& } \\
\text { Respiratory Disturbances }\end{array}$ & & \\
\hline Sweating & Sweating & 0.344 & 0.05 \\
Frequent yawning & Yawning ${ }^{* *}$ & 0.439 & $<0.001$ \\
Mottling & Mottling ${ }^{*}$ & 0.268 & $<0.001$ \\
Nasal stuffiness & Skin color ${ }^{*}$ & 0.273 & $<0.001$ \\
\hline Sneezing & Nasal Stuffiness ${ }^{* * *}$ & 0.593 & $<0.001$ \\
Nasal flaring & Sneezing ${ }^{* *}$ & 0.470 & $<0.001$ \\
\hline Gastrointestinal Disturbances & Nasal flaring ${ }^{* * *}$ & 0.677 & $<0.001$ \\
\hline Excessive sucking & & & \\
Stools & Sucking & 0.027 & 0.75 \\
Regurgitation & Stools ${ }^{* * *}$ & 0.554 & $<0.001$ \\
${ }^{*}$ Weak correlation $\left(0.1<\mathrm{r}_{\mathrm{s}}<0.3\right) .{ }^{* *}$ Moderate correlation $\left(0.3<\mathrm{r}_{\mathrm{s}}<0.5\right) .{ }^{* * *}$ Strong correlation $\left(\mathrm{r}_{\mathrm{s}}>0.5\right)$.
\end{tabular}

PCA of the FNASS suggested a three-factor solution that explained $26 \%$ of the variance with eigenvalues of 2.2, 1.5, and 1.4. The first factor had four items: high pitched cry (0.75), sleep after feeding (0.50), Moro reflex (0.69) and nasal flaring (0.79). The second factor had three items: disturbed tremors (0.54), excoriations $(-0.41)$, and fever $(-0.47)$. The third factor had two items: undisturbed tremors (0.55) and sneezing (0.50).

PCA of NNNS items that measure similar signs and symptoms of the FNASS also suggested a three-factor solution that explained $35.1 \%$ of the variance with eigenvalues of $3.7,1.5$, and 1.4. The first factor had six items: predominant state $(0.65)$, consolability $(-0.68)$, peak of excitement $(0.83)$, rapidity of build-up (0.68), irritability $(0.73)$, and sucking (0.58). The second factor had four items: Moro reflex (0.46), tremulousness (0.48), general tone (0.62), and mottling (0.68). The third factor had three items: sweating $(-0.49)$, nasal stuffiness (0.55), and loose or watery stools $(-0.48)$.

PCA of the NNNS and FNASS items combined suggested a five-factor solution that explained $33.1 \%$ of the variance with eigenvalues of 4.1, 2.5, 2.2, 2.0, and 1.8 (Table 3, Figure 1). The first factor contained seven items all measured by the NNNS: predominant state, consolability, peak of excitement, rapidity of build-up, irritability, general tone, and sucking. The second factor had four items all measured by the FNASS: high pitched cry, sleep after feeding, Moro reflex and nasal flaring. The third factor had five items: high-pitched cry (NNNS), disturbed tremors (FNASS), excoriation (FNASS) and mottling (NNNS and FNASS). The fourth factor had six items: tremulousness (NNNS), sweating (FNASS and NNNS), nasal stuffiness (NNNS), and loose or watery stools (NNNS and FNASS). The fifth factor had four items: undisturbed tremors (FNASS), sneezing (NNNS and FNASS) and gastric issues (FNASS). 
Table 3. Factor Loadings on FNASS and NNNS items.

\begin{tabular}{|c|c|c|c|c|c|}
\hline & \multicolumn{5}{|c|}{ Component } \\
\hline & Factor 1 & Factor 2 & Factor 3 & Factor 4 & Factor 5 \\
\hline Eigenvalue & 4.1 & 2.5 & 2.2 & 2.0 & 1.8 \\
\hline$\%$ Variance & 10.7 & 6.6 & 5.7 & 5.3 & 4.8 \\
\hline \multicolumn{6}{|c|}{ Central Nervous System Disturbances } \\
\hline High-pitched Crying (FNASS) & & 0.744 & & & \\
\hline High-pitched cry (NNNS) & & & -0.403 & & \\
\hline $\begin{array}{l}\text { First predominant State } \\
\text { (NNNS) }\end{array}$ & 0.611 & & & & \\
\hline $\begin{array}{l}\text { Consolability with } \\
\text { intervention (NNNS) }\end{array}$ & -0.582 & & & & \\
\hline Peak of excitement (NNNS) & 0.780 & & & & \\
\hline Rapidity of build-up (NNNS) & 0.751 & & & & \\
\hline Irritability (NNNS) & 0.816 & & & & \\
\hline Sleep after feeding (FNASS) & & 0.562 & & & \\
\hline Moro Reflex (FNASS) & & 0.625 & & & \\
\hline $\begin{array}{l}\text { Tremors: Undisturbed } \\
\text { (FNASS) }\end{array}$ & & & & & 0.586 \\
\hline Tremors: Disturbed (FNASS) & & & 0.405 & & \\
\hline Tremulousness (NNNS) & & & & 0.422 & \\
\hline $\begin{array}{l}\text { General tone-Predominant } \\
\text { tone (NNNS) }\end{array}$ & 0.522 & & & & \\
\hline Excoriation (FNASS) & & & -0.538 & & \\
\hline \multicolumn{6}{|c|}{ Metabolic/Vasomotor/Respiratory Disturbances } \\
\hline Sweating (FNASS) & & & & -0.530 & \\
\hline Sweating (NNNS) & & & & -0.552 & \\
\hline Mottling (FNASS) & & & 0.446 & & \\
\hline Mottling (NNNS) & & & 0.622 & & \\
\hline Nasal stuffiness (NNNS) & & & & 0.404 & \\
\hline Sneezing (FNASS) & & & & & 0.601 \\
\hline Sneezing (NNNS) & & & & & 0.465 \\
\hline Nasal Flaring (FNASS) & & 0.727 & & & \\
\hline \multicolumn{6}{|l|}{ Gastrointestinal Disturbances } \\
\hline Sucking (NNNS) & 0.489 & & & & \\
\hline Stools (FNASS) & & & & -0.522 & \\
\hline Gastric Issues (FNASS) & & & & & 0.516 \\
\hline $\begin{array}{l}\text { Loose stools, watery stools } \\
\text { (NNNS) }\end{array}$ & & & & -0.514 & \\
\hline
\end{tabular}




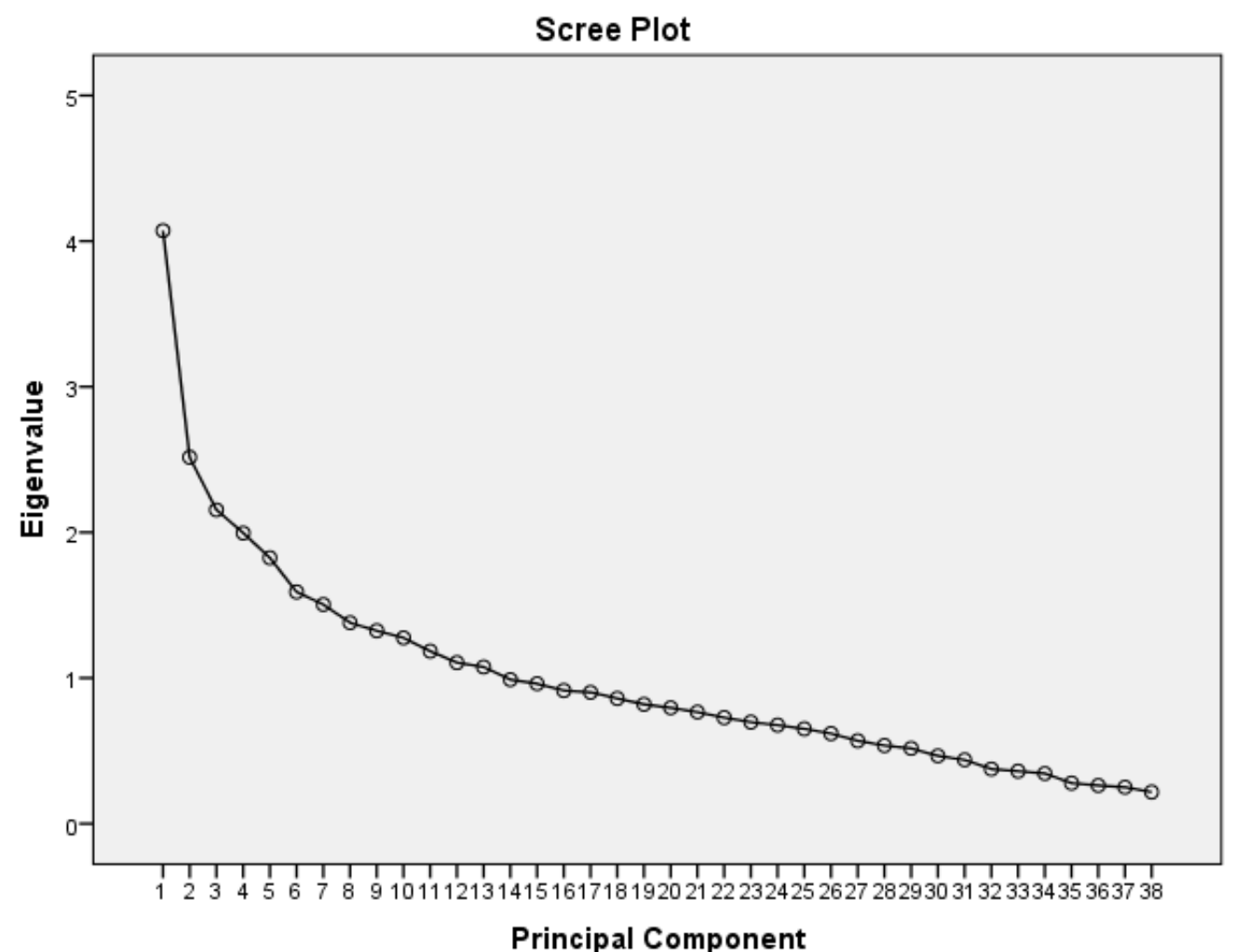

Figure 1. Scree plot from PCA of NNNS and FNASS.

\section{Discussion}

We conducted a survey of nurses who care for opioid-exposed infants and solicited their evaluation of the FNASS to determine the need for an improved instrument to measure and diagnose NAS. Many nurses did not think the FNASS accurately diagnosed NAS; the majority described the FNASS as subjective and more than half believed a new scoring method is needed for a more precise evaluation. Another interesting finding was the nurses' response to whether they thought that performing the FNASS in the mother's room compared to the nursery would change the score. This suggests that the subjectivity of the exam is not only due to the items on the exam but also to the environment in which the FNASS is conducted. Hospital conditions vary in this respect with some exams conducted in the mother's room, the nursery (where there are often other infants and additional distractions), or in a separate room such as a "feeding" room. When asked about scoring disagreements between nurses, half of the nurses reported there were many disagreements regarding the FNASS. Previous studies reported problems with reliability and validity of the FNASS that could compromise the clinical care and management of these infants [8]. Many inconsistencies in FNASS scoring have been reported and persisted even after training interventions at a six-month follow up in a previous study [9]. A 2014 study of nurses with $0-5$ years nursing experience found that reliability was not established for single FNASS measures. [17]. In our study, the number of years of performing the FNASS and number of years of nursing experience did not influence survey responses. In summation, this survey supports previous reports from clinicians who use the FNASS suggesting at the very least the FNASS needs improvement or that a new exam might be warranted.

The correlations between individual items on the FNASS with similar items on the NNNS showed 24 of 32 statistically significant correlations with most of the correlations at the moderate or weak level. The majority of the correlations that were moderate or weakly correlated were CNS items and several CNS items were not correlated at all although they measure the same behavior. This suggests that the two instruments measure similar constructs but vary in their precision and reliability of measurement. It is also noteworthy 
that since the NNNS is based on the handling and direct observation of the infant and not chart review or maternal report, only Finnegan items measured in the same manner were used so that measurement error due to chart review or maternal report was not a factor.

Results of the PCA showed that the factor analysis of the NNNS explained more variance than the factor analysis of the FNASS. The PCA of the FNASS and NNNS items combined did not increase the percent of variance explained over that of the NNNS alone. Factor 1, the strongest factor from the NNNS and FNASS combined, included only NNNS items, six out of seven of which were related to CNS characteristics. This is noteworthy and suggests that the NNNS is more sensitive to CNS than other symptoms of NAS. The factor analysis findings also suggest that the NNNS is a structurally and psychometrically more robust instrument than the FNASS. In addition, the NNNS provides a comprehensive assessment of the neurobehavioral repertoire of the infant by measuring functional domains. For example, factor 1 from the PCA of the NNNS alone included six items: predominant state, consolability, peak of excitement, rapidity of buildup, irritability, and sucking. These are functional domains that are important beyond the assessment of NAS. These results suggest the possibility of developing an NNNS-based tool to better characterize NAS and provide additional information about the infant's development.

The increase in NAS has shone the spotlight on diagnosis because treatment for NAS typically involves reintroduction of an opioid such as morphine. The infant then has to be weaned from morphine which can be a long, painful and expensive procedure. Falsepositive misdiagnosis of NAS can result in infants being unnecessarily treated with an opioid which means additional opioid exposure, longer hospital stays, increased costs, and mother-infant separation. False-negative misdiagnosis can result in infants not being treated when treatment is warranted. The danger here is that the infant is discharged and develops NAS at home, which would put the infant in danger and minimally require re-hospitalization.

The diagnosis of NAS is problematic because there is no "blood test" or other biomarkers, which forces us to rely on treating symptoms and clinical judgement. The FNASS has a long and storied history and originally was developed to determine the level of symptom severity that warranted pharmacological treatment [6]. Although the FNASS was not developed as a diagnostic tool, it has become the "gold standard" for the diagnosis of NAS as well. In fact, this distinction between the use of the FNASS as a diagnostic versus treatment tool is typically blurred. [18] This raises the question of whether we may need different metrics to diagnose NAS than to determine the threshold for the pharmacological treatment of NAS. In the absence of a biomarker, we have the mandate and the opportunity to revisit both the diagnosis and treatment of NAS based on the best current information that is available.

The concept of false positives and false negatives and measures of sensitivity and specificity do assume that there is a "gold standard." Yet, in the case of the Finnegan, another unaccounted-for problem is the role of clinical judgement in its use. Is the exam meant to be a "clinical assist" device to provide "guidance" for clinical decision making or is it meant to provide quantifiable criteria to determine when to start (and maintain) opioid treatment? [7] In practice, studies of treatment variation suggest that clinical judgement is not used systematically across hospitals, which contributes to the variability in the treatment of NAS and means we have no standard of care [19].

Our findings here showed similarities between the FNASS and the NNNS. They measure similar constructs and have similar factor structures but differ in reliability and validity. This could be due to the precise and reliable descriptors in the NNNS, where examiners maintain at least $90 \%$ agreement on the items. Independent systematic reviews have concluded that interrater reliability and test-retest reliability for the NNNS is strong and that the NNNS has robust psychometric properties [20,21]. In addition, the NNNS is based solely on direct handling and observation of the infant, whereas the FNASS also includes information derived from maternal reports and the medical record. Items on the FNASS are inadequately defined with poor psychometric properties that leave room for 
subjectivity $[9,17,22,23]$. A number of attempts have been made to improve the FNASS by shortening the exam and trying to include only the most salient items by using statistical methods to determine the contribution of individual Finnegan items [24-30]. However, this begs the question: salient for what? For pharmacological treatment? For diagnosis of NAS, or for both? There may be a different set of items necessary for the diagnosis versus pharmacological treatment issue and there are undoubtedly items that are correlated with diagnosis and/or treatment but may not be necessary for either. Moreover, the issue of the role of clinical judgement still needs to be addressed.

There are a number of strategies that could be used to develop, in the absence of biomarkers, an assessment tool that improves the accuracy and reliability of the FNASS that is provided by the NNNS. The NNNS is based only on the direct handling and observation of the infant and provides detailed, carefully constructed behavioral descriptions with established reliability and validity assured by a rigorous training model. These modifications would dramatically reduce the subjectivity inherent in the FNASS. This is the first study, to our knowledge, to evaluate Finnegan and NNNS performance in the same group of infants. In addition, as we have seen in this study, comparisons of findings between the FNASS and the NNNS show that there are, as expected, statistically significant correlations between the FNASS and the NNNS; however, the psychometric characteristics of the NNNS, as indicated by the results of the factor analysis, suggest that the NNNS is a more robust exam than the FNASS. Notable is the findings that the strongest factor (factor 1) was composed only of NNNS items and that across factors, the items that comprised these factors were CNS-related, perhaps suggesting that items related to CNS activity are the most salient in describing NAS.

The NNNS exam has been used in hundreds of studies across a wide range of at-risk infants, including infants with NAS [13,14]. The NNNS is being increasingly used in clinical settings both nationally and internationally [31]. The exam is used in many hospitals as part of standard care to help with the management of specific populations, notably preterm infants and infants with prenatal substance exposure. It is also used clinically on a referral basis during the infant's hospital stay and as part of discharge planning for the infant's health care provider and early intervention referral. Moreover, the NNNS has long term predictive validity initially shown to predict IQ and problem behavior at age 4.5 in cocaineand opioid-exposed infants [15]. Subsequent studies have confirmed the ability of the NNNS to forecast long-term developmental outcomes [32-43].

In conclusion, there seems to be widespread agreement that we need to improve our ability to assess and manage NAS and work toward developing a model of standard of care. In the absence of a biomarker, we must rely on symptoms, which is why trying to modify the Finnegan scale is a reasonable approach. We are suggesting a related but different approach which would not use the Finnegan items as they are but improve the measurement of those items that are determined to be most important by using an NNNSbased approach. The definitions, descriptions and scoring of items on the NNNS will likely improve the precision of measurement and enhance the psychometric properties of the tool. Moreover, the fact that the NNNS has been shown to predict long-term outcomes in infants with prenatal opioid exposure raises the possibility that an NNNS-based exam to diagnose NAS could ultimately be used to identify which infants with NAS are most likely to show long term developmental deficits [15]. The identification of these infants before hospital discharge could lead to the development of interventions to mitigate or prevent adverse developmental outcomes in infants with NAS. Critically, as suggested by Velez et al., the NNNS measures functional domains such as self-regulation that impact caregiver behavior and are important for later well-being [13]. Thus, an NNNS-based assessment of NAS could quantify specific strengths and weaknesses at the level of the individual infant that could identify functional neurobehavioral domains to target for intervention. Sharing this kind of information with caregivers could also strengthen the developing infant caregiver relationship and provide the bases for additional non-pharmacological care. 
Supplementary Materials: The following are available online at https:/ / www.mdpi.com/article/10 .3390 / children8080685/s1, supplementary: Nursing opinion on the finnegan score survey.

Author Contributions: Conceptualization, C.A.C.F., B.M.L., E.L.O. and K.H.; formal analysis, L.M.D.; resources, B.M.L. data curation, C.A.C.F., E.L.O. and L.M.D.; writing-original draft preparation, C.A.C.F., B.M.L. and L.M.D.; writing-review and editing, C.A.C.F., B.M.L., E.L.O., L.M.D. and K.H.; supervision, B.M.L. All authors have read and agreed to the published version of the manuscript.

Funding: This research received no external funding.

Institutional Review Board Statement: The study was conducted according to the guidelines of the Declaration of Helsinki and approved by the Institutional Review Board of Women and Infants Hospital in Providence, RI (945325-1 and 9/23/2016).

Informed Consent Statement: Patient consent was waived due to the research presenting no more than minimal risk of harm to subjects and involves no procedures for which written consent is normally required outside of the research context.

Data Availability Statement: Data sharing not applicable.

Conflicts of Interest: The authors declare no conflict of interest.

\section{References}

1. Patrick, S.W. The triple aim for neonatal abstinence syndrome. J. Pediatr. 2015, 167, 1189-1191. [CrossRef]

2. Patrick, S.W.; Schumacher, R.E.; Benneyworth, B.D.; Krans, E.E.; McAllister, J.M.; Davis, M.M. Neonatal abstinence syndrome and associated health care expenditures: United States, 2000-2009. JAMA 2012, 307, 1934-1940. [CrossRef] [PubMed]

3. Villapiano, N.L.G.; Winkelman, T.; Kozhimannil, K.B.; Davis, M.M.; Patrick, S.W. Rural and urban differences in neonatal abstinence syndrome and maternal opioid use, 2004 to 2013. JAMA Pediatr. 2017, 171, 194-196. [CrossRef]

4. Winkelman, T.N.A.; Villapiano, N.; Kozhimannil, K.B.; Davis, M.M.; Patrick, S.W. Incidence and costs of neonatal abstinence syndrome among infants with Medicaid: 2004-2014. Pediatrics 2018, 141, e20173520. [CrossRef]

5. Jansson, L.M.; Patrick, S.W. Neonatal abstinence syndrome. Pediatr. Clin. N. Am. 2019, 66, 353-367. [CrossRef]

6. Finnegan, L.P.; Kron, R.E.; Connaughton, J.F.; Emich, J.P. Assessment and treatment of abstinence in the infant of the drugdependent mother. Int. J. Clin. Pharm. Biopharm. 1975, 12, 19-32.

7. Kaltenbach, K.; Jones, H.E. Neonatal abstinence syndrome. J. Addict. Med. 2016, 10, 217-223. [CrossRef] [PubMed]

8. Bagley, S.M.; Wachman, E.M.; Holland, E.; Brogly, S.B. Review of the assessment and management of neonatal abstinence syndrome. Addict. Sci. Clin. Pract. 2014, 9, 19. [CrossRef]

9. Timpson, W.; Killoran, C.; Maranda, L.; Picarillo, A.; Bloch-Salisbury, E. A quality improvement initiative to increase scoring consistency and accuracy of the Finnegan tool: Challenges in obtaining reliable assessments of drug withdrawal in neonatal abstinence syndrome. Adv. Neonatal Care Off. J. Natl. Assoc. Neonatal Nurses 2018, 18, 70-78. [CrossRef] [PubMed]

10. Reddy, U.M.; Davis, J.M.; Ren, Z.; Greene, M.F. Opioid use in pregnancy, neonatal abstinence syndrome, and childhood outcomes: Executive summary of a joint workshop by the Eunice Kennedy Shriver National Institute of Child Health and Human Development, American College of Obstetricians and Gynecologists, American Academy of Pediatrics, Society for Maternal-Fetal Medicine, Centers for Disease Control and Prevention, and the March of Dimes Foundation. Obstet. Gynecol. 2017, 130, 10-28. [PubMed]

11. Grim, K.; Harrison, T.E.; Wilder, R.T. Management of neonatal abstinence syndrome from opioids. Clin. Perinatol. 2013, 40, 509-524. [CrossRef]

12. Lester, B.M.; Tronick, E.Z.; Brazelton, T.B. The neonatal intensive care unit network neurobehavioral scale procedures. Pediatrics 2004, 113, 641-667.

13. Velez, M.L.; McConnell, K.; Spencer, N.; Montoya, L.; Tuten, M.; Jansson, L.M. Prenatal buprenorphine exposure and neonatal neurobehavioral functioning. Early Hum. Dev. 2018, 117, 7-14. [CrossRef] [PubMed]

14. Coyle, M.G.; Salisbury, A.L.; Lester, B.M.; Jones, H.E.; Lin, H.; Graf-Rohrmeister, K.; Fischer, G. Neonatal neurobehavior effects following buprenorphine versus methadone exposure. Addiction 2012, 107, 63-73. [CrossRef] [PubMed]

15. Liu, J.; Bann, C.; Lester, B.; Tronick, E.; Das, A.; Lagasse, L.; Bauer, C.; Shankaran, S.; Bada, H. Neonatal neurobehavior predicts medical and behavioral outcome. Pediatrics 2009, 125, e90-e98. [CrossRef] [PubMed]

16. IBM Corp. IBM SPSS Statistics for Windows; Version 24.0; IBM Corp.: Armonk, NY, USA, 2016.

17. Retskin, C.M.; Wright, M.E. Interobserver reliability of the Finnegan neonatal abstinence scoring tool in an acute care setting. J. Obstet. Gynecol. Neonatal Nurs. 2014, 43, S61. [CrossRef]

18. Doherty, K.M.; Scott, T.A.; Morad, A.; Crook, T.; McNeer, E.; Lovell, K.S.; Gay, J.C.; Patrick, S.W. Evaluating definitions for neonatal abstinence syndrome. Pediatrics 2021, 147. [CrossRef]

19. Patrick, S.W.; Kaplan, H.C.; Passarella, M.; Davis, M.M.; Lorch, S.A. Variation in treatment of neonatal abstinence syndrome in US children's hospitals, 2004-2011. J. Perinatol. 2014, 34, 867-872. [CrossRef] [PubMed] 
20. Eeles, A.L.; Olsen, J.E.; Walsh, J.M.; McInnes, E.K.; Molesworth, C.M.L.; Cheong, J.L.Y.; Doyle, L.W.; Spittle, A.J. Reliability of neurobehavioral assessments from birth to term equivalent age in preterm and term born infants. Phys. Occup. Ther. Pediatr. 2017, 37, 108-119. [CrossRef] [PubMed]

21. Noble, Y.; Boyd, R. Neonatal assessments for the preterm infant up to 4 months corrected age: A systematic review. Dev. Med. Child Neurol. 2012, 54, 129-139. [CrossRef] [PubMed]

22. Jones, H.E.; Fielder, A. Neonatal abstinence syndrome: Historical perspective, current focus, future directions. Prev. Med. 2015, 80, 12-17. [CrossRef]

23. Verklan, M.T. Time for the Finnegan Neonatal Abstinence Syndrome Scoring tool to be retired? J. Périnat. Neonatal Nurs. 2019, 33, 276. [CrossRef] [PubMed]

24. Zahorodny, W.; Rom, C.; Whitney, W.; Giddens, S.; Samuel, M.; Maichuk, G.; Marshall, R. The neonatal withdrawal inventory: A simplified score of newborn withdrawal. J. Dev. Behav. Pediatr. 1998, 19, 89-93. [CrossRef] [PubMed]

25. Jones, H.E.; Seashore, C.; Johnson, E.; Horton, E.; O'Grady, K.E.; Andringa, K.; Grossman, M.R.; Whalen, B.; Holmes, A.V. Psychometric assessment of the Neonatal Abstinence Scoring System and the MOTHER NAS Scale. Am. J. Addict. 2016, 25, 370-373. [CrossRef] [PubMed]

26. Devlin, L.A.; Breeze, J.L.; Terrin, N.; Gomez Pomar, E.; Bada, H.; Finnegan, L.P.; O’Grady, K.E.; Jones, H.E.; Lester, B.; Davis, J.M. Association of a Simplified Finnegan Neonatal Abstinence Scoring Tool with the need for pharmaco-logic treatment for neonatal abstinence syndrome. JAMA Netw. Open 2020, 3, e202275. [CrossRef] [PubMed]

27. Gomez Pomar, E.; Finnegan, L.P.; Devlin, L.; Bada, H.; Concina, V.A.; Ibonia, K.T.; Westgate, P.M. Simplification of the Finnegan Neonatal Abstinence Scoring System: Retrospective study of two institutions in the USA. BMJ Open 2017, 7, e016176. [CrossRef]

28. Maguire, D.; Cline, G.; Parnell, L.; Tai, C.-Y. Validation of the Finnegan Neonatal Abstinence Syndrome Tool—Short Form. Adv. Neonatal Care 2013, 13, 430-437. [CrossRef] [PubMed]

29. Chervoneva, I.; Adeniyi-Jones, S.C.; Blanco, F.; Kraft, W.K. Development of an abbreviated symptom score for the neonatal abstinence syndrome. J. Perinatol. 2020, 40, 1031-1040. [CrossRef] [PubMed]

30. Suresh, S.; Anand, K. Opioid tolerance in neonates: A state-of-the-art review. Pediatr. Anesth. 2001, 11, 511-521. [CrossRef]

31. Boukydis, C.F.Z.; Bigsby, R.; Lester, B.M. Clinical use of the Neonatal Intensive Care Unit Network Neurobehavioral Scale. Pediatrics 2004, 113, 679-689.

32. Stephens, B.E.; Liu, J.; Lester, B.; Lagasse, L.; Shankaran, S.; Bada, H.; Bauer, C.; Das, A.; Higgins, R. Neurobehavioral assessment predicts motor outcome in preterm infants. J. Pediatr. 2010, 156, 366-371. [CrossRef] [PubMed]

33. El-Dib, M.; Massaro, A.N.; Glass, P.; Aly, H. Neurobehavioral assessment as a predictor of neurodevelopmental outcome in preterm infants. J. Perinatol. 2012, 32, 299-303. [CrossRef]

34. Lester, B.M.; Bagner, D.M.; Liu, J.; Lagasse, L.L.; Seifer, R.; Bauer, C.R.; Shankaran, S.; Bada, H.; Higgins, R.D.; Das, A. Infant neurobehavioral dysregulation: Behavior problems in children with prenatal substance exposure. Pediatrics 2009, 124, 1355-1362. [CrossRef]

35. Bowers, K.; Khoury, J.; Sucharew, H.; Xu, Y.; Chen, A.; Lanphear, B.; Yolton, K. Early infant attention as a predictor of social and communicative behavior in childhood. Int. J. Behav. Dev. 2018, 43, 204-211. [CrossRef]

36. Kiblawi, Z.N.; Smith, L.M.; Diaz, S.D.; LaGasse, L.L.; Derauf, C.; Newman, E.; Shah, R.; Arria, A.; Huestis, M.; Haning, W.; et al. Prenatal methamphetamine exposure and neo-natal and infant neurobehavioral outcome: Results from the IDEAL study. Subst. Abus. 2014, 35, 68-73. [CrossRef]

37. Millerloncar, C.; Lester, B.; Seifer, R.; Lagasse, L.; Bauer, C.; Shankaran, S.; Bada, H.; Wright, L.; Smeriglio, V.; Bigsby, R. Predictors of motor development in children prenatally exposed to cocaine. Neurotoxicol. Teratol. 2005, 27, 213-220. [CrossRef] [PubMed]

38. Picciolini, O.; Porro, M.; Meazza, A.; Giannì, M.L.; Rivoli, C.; Lucco, G.; Barretta, F.; Bonzini, M.; Mosca, F. Early exposure to maternal voice: Effects on preterm infants development. Early Hum. Dev. 2014, 90, 287-292. [CrossRef]

39. Pineda, R.; Bender, J.; Hall, B.; Shabosky, L.; Annecca, A.; Smith, J. Parent participation in the neonatal intensive care unit: Predictors and relationships to neurobehavior and developmental outcomes. Early Hum. Dev. 2018, 117, 32-38. [CrossRef] [PubMed]

40. Pineda, R.G.; Neil, J.; Dierker, D.; Smyser, C.D.; Wallendorf, M.; Kidokoro, H.; Reynolds, L.C.; Walker, S.; Rogers, C.; Mathur, A.M.; et al. Alterations in brain structure and neurodevelopmental outcome in preterm infants hospitalized in different neonatal intensive care unit environments. J. Pediatr. 2014, 164, 52-60.e2. [CrossRef]

41. Ryckman, J.; Hilton, C.; Rogers, C.; Pineda, R. Sensory processing disorder in preterm infants during early childhood and relationships to early neurobehavior. Early Hum Dev. 2017, 113, 18-22. [CrossRef]

42. Salley, B.; Sheinkopf, S.J.; Neal-Beevers, A.R.; Tenenbaum, E.J.; Miller-Loncar, C.L.; Tronick, E.; Lagasse, L.L.; Shankaran, S.; Bada, H.; Bauer, C.; et al. Infants' early visual attention and social engagement as developmental precursors to joint attention. Dev. Psychol. 2016, 52, 1721-1731. [CrossRef] [PubMed]

43. Sucharew, H.; Khoury, J.C.; Xu, Y.; Succop, P.; Yolton, K. NICU Network neurobehavioral scale profiles predict developmental outcomes in a low-risk sample. Paediatr. Périnat. Epidemiol. 2012, 26, 344-352. [CrossRef] [PubMed] 